\title{
Understanding spatial presence formation and maintenance in virtual reality for younger and older adults
}

\author{
Tracy L. Mitzner PhD ${ }^{a}$, Sean A. McGlynn PhD ${ }^{b}$, Wendy A. Rogers PhD ${ }^{c, *}$ \\ ${ }^{a}$ Center for Inclusive Design and Innovation, Georgia Institute of Technology, Georgia, \\ USA; ${ }^{b}$ School of Psychology, Georgia Institute of Technology, Georgia, USA; ${ }^{c}$ College of \\ Applied Health Sciences, University of Illinois Urbana Champaign, Illinois, USA; *Corre- \\ sponding author: wendyr@illinois.edu
}

\begin{abstract}
Background: Virtual reality (VR) has the potential to benefit physical, cognitive, and socioemotional well-being across a wide spectrum of domains. For the benefits of VR to be fully realized, people must experience spatial presence in the digital environment. We developed the Magnet Model of Spatial Presence as a framework to integrate the extant literature, identify gaps, and delineate the spatial presence formation and maintenance processes in virtual reality. Given that perception and attention are key components of the spatial presence process, age-related changes in these abilities might impact older adults' ability to develop and maintain spatial presence in a virtual environment.

Objective: This research study aimed to address limitations in the literature by assessing various aspects of the spatial presence process for younger and older adults. The objectives were to evaluate how long it takes to form spatial presence; the extent that spatial presence is experienced and if it changes over several hours of time with experience; how well people maintain presence; and how well they recover from breaks in the spatial presence experience.

Method: Participants were twenty-five younger adults and twenty-five older adults. The VR apparatus was an HTC Vive and the VR experiences included one passive experience and one active experience. Participation occurred for three days.

Results: Most aspects of the spatial presence process were similar for older and younger adults. Presence formation occurred quickly, levels of presence were high and generally maintained over several hours of time. Younger adults experienced more breaks in presence than older adults, but all participants were generally able to easily recover from breaks in presence.

Conclusion: These findings provide insights on presence formation, levels, maintenance, and break recovery. The results illustrate the potential of virtual reality for both younger and older adults.
\end{abstract}

Keywords: virtual reality (VR), spatial presence, aging

\section{INTRODUCTION}

The harmony of sensory information across different modalities is what helps provide people with a sense of where they are and what they can do in a given place. Technologies, such as virtual reality (VR), can simulate this accumulation of multi-modal information; creating the sensation of being physically located and the ability to physically act within a digital environment. Although early applications of VR were geared toward a younger demographic (i.e., gaming), VR has the potential to benefit physical, cognitive, and socio-emotional well-being for people of all ages across various domains. These applications include training (Satava, 1995); education (Wickens, 1992); healthcare and wellness (Chirico et al., 2016; Jungjin Kim, Son, Ko, \& Yoon, 2013; Satava, 1995); the military (Baumann, 1993); com- munication (Biocca, 1992), manufacturing (Gavish et al., 2015); and entertainment (Bates, 1992).

Many VR applications may benefit older adults, particularly. VR can be used for virtual exercise programs (Sakhare, Yang, Stradford, et al., 2019; Bruun-Pedersen, Serafin, Maculewicz, et al., 2016), which can have similar benefits as traditional workout techniques (Plante, Aldridge, Bogden, \& Hanelin, 2003) with additional benefits for mood, and can be more enjoyable and motivating than traditional techniques (Molina, Ricci, de Moraes, \& Perracini, 2014; Plante et al., 2003). VR has been used with older adults for easing chronic pain (Hoffman et al., 2004), training gait and balance (Hoffman et al., 2004), and training motor control (De Bruin, Schoene, Pichierri, \& Smith, 2010). VR has been used for cognitive 
screening to detect early declines by assessing visuospatial navigation skills (McGee et al., 2000) and walking performance (Kim, Jang, Kim, Jung, \& You, 2009). There is evidence that VR can be used as a cognitive rehabilitation tool, as well, for correcting post-stroke hemispheric neglect (Kim et al., 2007). Lastly, socio-emotional applications of VR for older adults include remote travel to tourist locations and museums (Guttentag, 2010), social interaction with friends and family (Schroeder, 2002), a distraction from chemotherapy (Schneider \& Hood, 2007), fear exposure therapies (Hodges et al., 1995), and treating anxiety and depression (Hoffman et al., 2004).

\section{Spatial presence is critical to VR success}

Virtual reality has been defined as a real or simulated environment in which a perceiver experiences [tele]presence (Steuer, 1992). For VR applications to be effective, the user must experience a sense of being physically located in the digital environment. This subjective experience is referred to as spatial presence (or just "presence") and is considered to be the primary goal of VR.

Spatial presence is a psychological experience, during which perceived self-location and perceived action possibilities are connected to a virtual spatial environment, and mental capacities are bound by the virtual environment instead of reality. As the computational capacity of VR systems continues to rapidly improve, such that simulating sensory stimuli becomes increasingly feasible, variation in spatial presence will likely be more dependent on the characteristics and abilities of the person using VR than on the qualities of the VR itself (i.e., immersiveness).

Eliciting presence is the central goal of VR because there is evidence that in many virtual applications, the outcomes are dependent on or improved when presence is experienced (Slater \& Wilbur, 1997). Indeed, using VR exposure therapy as a phobia intervention showed that higher degrees of phobia-eliciting triggers were related to increased ratings of discomfort and frequency of physical anxiety symptoms, which are critical for treatment efficacy (Hodges et al., 1995). Therapies tend to be more easily accepted if presence is experienced (Stanney, Mourant, \& Kennedy, 2006). Presence is positively correlated with enjoyment in virtual museum tours (Sylaiou, Mania, Karoulis, \& White, 2010). Digital content is more persuasive for people who experience presence (Kim \& Biocca, 1997). Feeling present can also lead to better performance, depending on the requirements of the task (Bystrom, Barfield, \& Hendrix, 1999; Stanney \& Salvendy, 1998). Finally, increasing the sense of presence experienced is thought to lead to higher quality training outcomes (Wallis \& Tichon, 2013; Witmer \& Singer, 1998).

\section{Spatial presence and aging}

Given that perception and attention are key components of the spatial presence process, age-related changes in these abilities (Czaja, Boot, Charness, \& Rogers, 2019) might impact older adults' ability to develop and maintain a spatial presence in a virtual environment. However, there is limited research on the spatial presence and person factors, including age (Giovannetti Yamaguchi, Roll et al., 2019; Kothgassner, Goreis, Kafka, et al. 2018). It is an open question whether older adults experience sufficient levels of presence to benefit from VR.

A two-stage spatial presence model proposed by Wirth et al. (2007) theorized that the focus of attention on the virtual environment enables people to develop a spatial mental model of the environment. In the first stage, people attend to and process spatial cues (e.g., occlusion, interaural level/time differences) in the virtual environment, which help create and continuously update spatial representations of that environment. In the second stage, people begin testing perceptual hypotheses of self-location and possibilities to act within the virtual environment. Spatial presence occurs if people confirm these perceptual hypotheses, such that the virtual environment is their primary egocentric reference frame (i.e., perceived self-location, perceived possible actions and mental capacities are all bound to the mediated space; (Wirth et al., 2007).

A key contribution of the Wirth et al. (2007) model was the separation of attentional resource allocation into automatic and controlled attention processes. For example, if people are inherently more interested in the domain represented in the virtual environment, they may devote more attention to that environment. Although Wirth et al. (2007) mentioned that other personal factors such as intelligence, age, and gender could also impact presence via effects on automatic and controlled processes, the specific variables and mechanisms through which they might influence presence have been relatively underspecified in models of presence. We developed the Magnet Model of Spatial Presence (MMSP; Figure 1;) (McGlynn, 2019), which builds upon the strengths of the Wirth et al. (2007) model by adding person variables that have been shown to influence presence and hypothesize the mechanisms through which they might impact aspects of spatial presence (i.e., presence formation, maintenance, break recovery). The primary components of the model are as follows:

\section{Physical \& virtual magnets}

The physical environment and the virtual environment compete, or 'magnetically pull' upon, the spatial presence of a person via physical and 


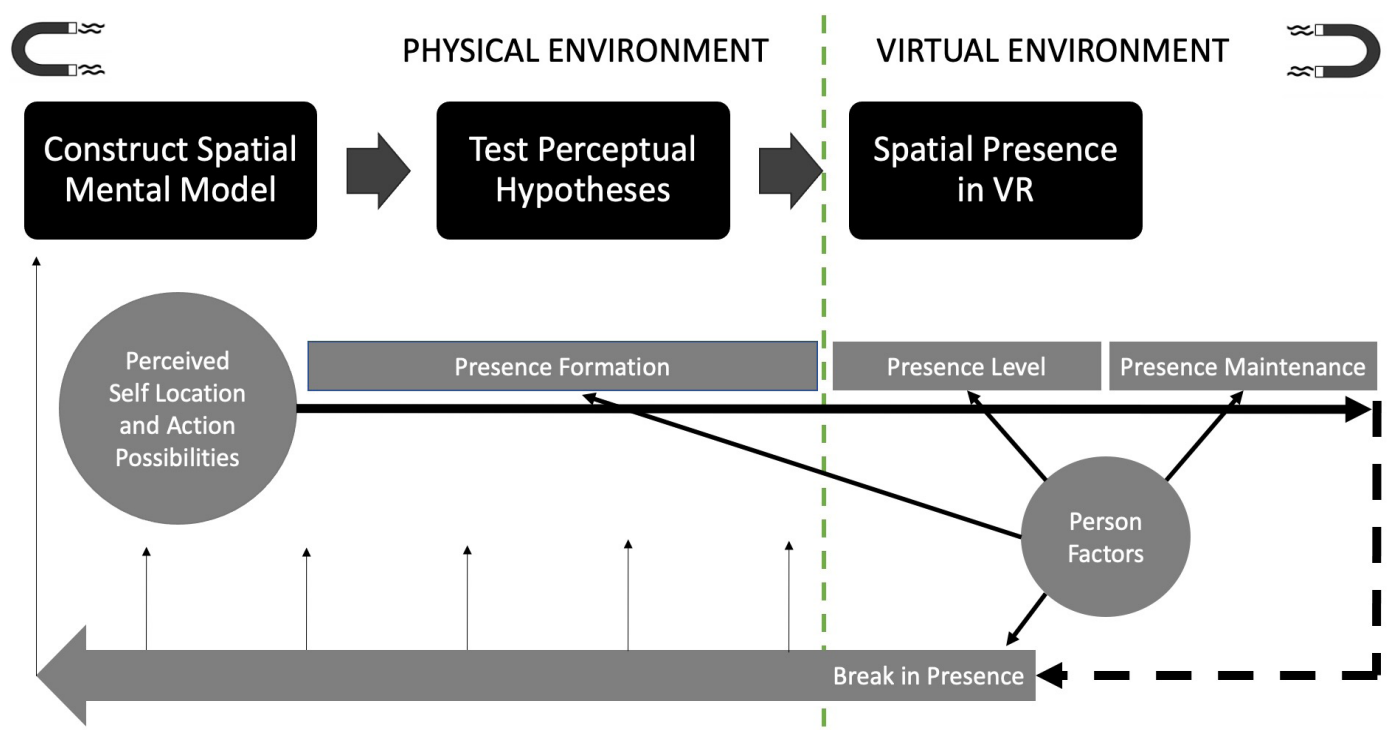

Figure 1. Magnet model of spatial presence as framework to understand spatial presence formation and maintenance in virtual reality

virtual stimuli, respectively. The stimuli coming from the physical and virtual environments determine the strength of the pull. More specifically, the strength of the pull is dictated by a combination of the salience of the stimuli and the extent to which the user perceives the nature of that stimuli to align with a mental model of being virtually present or physically present.

(1) Physical stimuli: Stimuli that originate in the physical environment.

(2) Virtual stimuli. Stimuli originate in the virtual environment.

(3) Signal. Stimuli from either the physical or virtual environment provide evidence of one's location in the virtual environment. For example, a person who is in a virtual kitchen experience could hear glass breaking in the physical experience, and that stimuli in the physical environment could still provide evidence for the virtual environment.

(4) Noise. Stimuli from either the physical or virtual environment provide evidence of one's location in the physical environment. With respect to the example above, if the person was in an underwater experience when they heard the glass breaking in the physical experience, that stimuli in the physical environment would provide evidence for the physical environment.

\section{Focus of attention}

People can focus attention (may be automatic or controlled) on the incoming stimuli from the physical and virtual environments.

\section{Stimulus classification}

On a moment-to-moment basis, the information that is attended to can either be classified as originating in the physical environment (noise) or as originating in the virtual environment (signal). The per- ceptual hypotheses regarding perceived body and actions are tested on the basis of this information.

\section{Perceived body \& actions}

Information classified as virtual will move individuals' perceived body and action possibilities (i.e., their spatial presence) in the positive direction, closer to the threshold. If this occurs consistently, the threshold will be crossed, indicating that the person has accepted the virtual environment as the primary egocentric reference frame (i.e., spatial presence is being experienced). Information classified as physical will move the individual's perceived body and action possibilities in the negative direction, further away from the threshold. If this occurs consistently, they will maintain the physical environment as the primary egocentric reference frame.

\section{System immersiveness/threshold}

The threshold represents the binary nature of spatial presence, the point at which virtual spatial presence is either on or off. The more immersive the system, the lower the threshold will be, indicating that it should take less time for spatial presence to occur. This time reduction is a result of a shorter amount of time needed to go through the stages of the Wirth (2007) model. Specifically, highly immersive systems project rich multimodal stimuli that result in less time people need to spend constructing a spatial mental model of the virtual environment and testing the perceptual hypotheses.

\section{Break in presence}

The processes of focusing attention and classifying stimuli continue even after the threshold is crossed and people are experiencing spatial 
presence. Thus, it is possible for a break in presence to occur, such that a person becomes suddenly aware of their actual location in the physical environment (Slater \& Steed, 2000). When these breaks do occur, they may vary in strength such that they restart the entire formation process, shift the perceived body and actions to just below the threshold (regaining presence will be fairly quick and easy), or anywhere in between these two extremes.

\section{Person factors}

A variety of personal factors can influence this process, via two primary mechanisms. First, person variables can influence the ease of induction, such that certain individuals will be more likely than others to experience presence. Second, certain individuals will be more or less able to maintain presence, such that some individuals might not experience a break in response to the same conflicting stimuli or event that causes a break in a different person. Similarly, individuals will vary in the extent that a break is detrimental to their experience (i.e., how far back in the process a break sets a person) and in how quickly they can recover from a break (i.e., regain presence).

To summarize the model, people continuously focus attention on and classify incoming stimuli from both the physical and virtual environment (which are 'pulling' for their spatial presence). If the stimuli are consistently classified as virtual, people will cross the threshold (which depends on the immersiveness of the system) and experience presence, such that the virtual environment becomes their primary egocentric reference frame. If the threshold is crossed in the opposite direction (the physical environment becomes the primary egocentric reference frame), a break in presence has occurred, and these breaks may vary in strength. Certain aspects of the process are dependent on personal factors. People will differ in the ease with which they can experience presence (i.e., presence formation), how present they become (i.e., presence level), their susceptibility to breaks in the presence (i.e., presence maintenance), and how well they recover after a break in presence has occurred. The strengths of the MMSP are in explicating the potential roles of personal factors and the incorporation of presence maintenance and recovery from breaks.

\section{Overview of study}

The overarching goal of this research was to understand the role of person factors in presence formation, level, maintenance, and break recovery. This research empirically tested components of the MMSP as a first step toward understanding how differences in perception and attention might influence spatial presence at various stages of the process, using age as a proxy for these dif- ferences. The following research questions were addressed, with a specific focus on comparing younger adults and older adults:

- How long does it take for spatial presence formation to occur?

- To what extent do people experience spatial presence?

- To what extent do levels of presence change over time (e.g., for several hours)?

- Once spatial presence is being experienced, how well do people maintain it?

- If there is a break in spatial presence, how easy is it to regain?

These questions were addressed in a 3-day study in which younger and older adults completed cognitive and perceptual ability assessments, participated in passive and active immersive VR experiences, and completed multiple measures related to spatial presence, including the level of presence and breaks in presence.

\section{Method \\ Participants}

Twenty-five younger adults (10 female, 15 male; $M=20$ years of age, $S D=1.66$, Range $=18-23$ ) from the Georgia Institute of Technology undergraduate population participated in this study and received course credit for their participation. Twenty-five older adults (17 female, 8 male; $M$ $=73.7$ years of age, $\mathrm{SD}=3.51$, Range $=69-79$ ) were recruited from the Human Factors and Aging Laboratory participant registry and received $\$ 90$ in compensation for their time after the study. Participants were excluded if they owned a virtual reality system or had used virtual reality more than once. Participants were generally healthy, educated, and frequent users of technology. This project was part of a dissertation, and more details are available in McGlynn (2019).

\section{VR system}

The immersive VR system used was the HTC Vive, which included a head-mounted display (HMD) with headphones, two motion-tracked controllers, and two cameras. The HMD has two screens (one for each eye) with a combined resolution of $2160 \times 1200,90 \mathrm{~Hz}$ refresh rate, and 110-degree field of view. Over-ear headphones provided directional audio and the HTC Vive controllers provided haptic feedback. The cameras enabled room-scale 360-degree motion tracking of the HMD and controllers. The system was powered using a CYBERPOWERPC Gamer Xtreme GXi10180A Desktop Gaming PC (Intel i7-7700 3.6GHz, NVIDIA GTX 1060 3GB, 8GB DDR4 RAM, 1TB 7200RPM HDD, Win 10 Home).

\section{Virtual experiences}

There were two different virtual experiences used in this study: namely, a task-free experience and 
Table 1. Materials and corresponding constructs

\begin{tabular}{|c|c|}
\hline Construct & Measures \\
\hline Participant characteristics & Demographics, health, and technology experience (Czaja et al., 2006) \\
\hline VR familiarity & $\begin{array}{l}\text { Developed to assess familiarity with a variety of virtual reality systems (e.g., HTC } \\
\text { Vive, Google Cardboard, PlayStation VR, Oculus Rift) (McGlynn, 2019) }\end{array}$ \\
\hline $\begin{array}{l}\text { Cognitive and perceptual } \\
\text { abilities }\end{array}$ & $\begin{array}{l}\text { Useful Field of View (Edwards et al., 2005) } \\
\text { Eriksen Flanker Task and Stroop Task (Verbruggen, Liefooghe, \& Vandierendonck, } \\
\text { 2004) } \\
\text { Trail Making Tests A and B (Sanchez-Cubillo et al., 2009; Tombaugh, 2004) } \\
\text { Cube Comparison Test (French, Ekstrom, \& Price, 1963) }\end{array}$ \\
\hline Immersive tendencies & Immersive tendencies questionnaire (Witmer \& Singer, 1998) \\
\hline Levels of spatial presence & MEC-spatial presence questionnaire (MEC-SPQ) (Vorderer et al., 2004) \\
\hline $\begin{array}{l}\text { Spatial presence, } \\
\text { involvement, and realness }\end{array}$ & Group presence questionnaire (IPQ; (Schubert, Friedmann, \& Regenbrecht, 2001) \\
\hline Breaks in presence & $\begin{array}{l}\text { Break counter (Slater \& Steed, 2000) } \\
\text { Retrospective presence slider (IJsselsteijn, de Ridder, Hamberg, Bouwhuis, \& } \\
\text { Freeman, 1998) } \\
\text { Break susceptibility/recovery questionnaire (McGlynn, 2019) }\end{array}$ \\
\hline Positive and negative affect & $\begin{array}{l}\text { I-PANAS-SF (Thompson, 2007). Inclusion of this scale was exploratory and not } \\
\text { used in the analyses for this study. }\end{array}$ \\
\hline Simulator sickness & $\begin{array}{l}\text { No participants indicated that they were experiencing any of the symptoms more } \\
\text { than slightly, so no study sessions were affected due to simulator sickness. This } \\
\text { questionnaire was not included in the analysis. }\end{array}$ \\
\hline Subjective workload & NASA-TLX (Hart \& Staveland, 1988) \\
\hline $\begin{array}{l}\text { Subjective experience of } \\
\text { presence }\end{array}$ & $\begin{array}{l}\text { Semi-structured interview queried about their experience of presence in the study } \\
\text { (e.g., what enhanced and detracted from it, how long it took them to first } \\
\text { experience it, the extent that it was experienced throughout the study). Interview } \\
\text { script available in McGlynn (2019). }\end{array}$ \\
\hline
\end{tabular}

an active experience. The task-free experience was used to provide participants (who were all VR novices) with a sense of what it felt like to wear the headset and be in VR without needing to do anything or use the controllers, as well as an opportunity to become familiar with the postexperience questionnaires. "The Blu: Whale Encounter" was used as the task-free virtual experience (hereafter referred to as the "passive VR session"), during which participants were underwater on the deck of a sunken ship and were able to look around at various ocean creatures, culminating with a whale swimming up to the side of the ship before continuing to swim away. The active experience was the "VR The Diner Duo" by Whirlybird. The premise of the game is the user is a hamburger chef in a diner who needs to complete customers' orders and hand them to a server for delivery. Completing the orders required viewing the orders, preparing order items (i.e., chopping or cooking), placing prepared items in the correct sequence on a plate, and handing the order to a server using a controller.

\section{Materials}

The materials and corresponding constructs used in the study are presented in Table 1.

\section{Procedure}

Participants provided consent and completed several questionnaires, including demographics, health, technology experience, virtual reality familiarity, the immersive tendencies question- naire, and the visual-spatial imagery dimension of the MEC-SPQ. The study took part for three days. Each day included:

- Cognitive and perceptual ability assessments

- A passive VR session

- An active VR training session

- An active VR criterion test session

- An active VR experimental session

Participants were first given a tutorial about the VR experience and using the controls. Next, participants completed the active VR training session, during which they were allowed to ask the experimenter questions and for assistance as needed. Once the participant had completed the training tasks successfully, they received a 5 -minute break and then participated in the active VR criterion test session. Participants met the criterion if they were able to complete at least three sandwich orders without receiving a Game Over and without experimenter intervention. If the participant did not meet the criterion, the same training followed by the criterion test session process was completed again. Once the participant passed the criterion test session, they were given another 5-minute break, and then the 10-minute active VR experimental session began (without assistance from the experimenter).

The post-experience questionnaire included the MEC-SPQ, IPQ, SSQ, NASA-TLX, and I-PANAS$\mathrm{SF}$, and was administered after each passive VR session and each active VR experimental ses- 


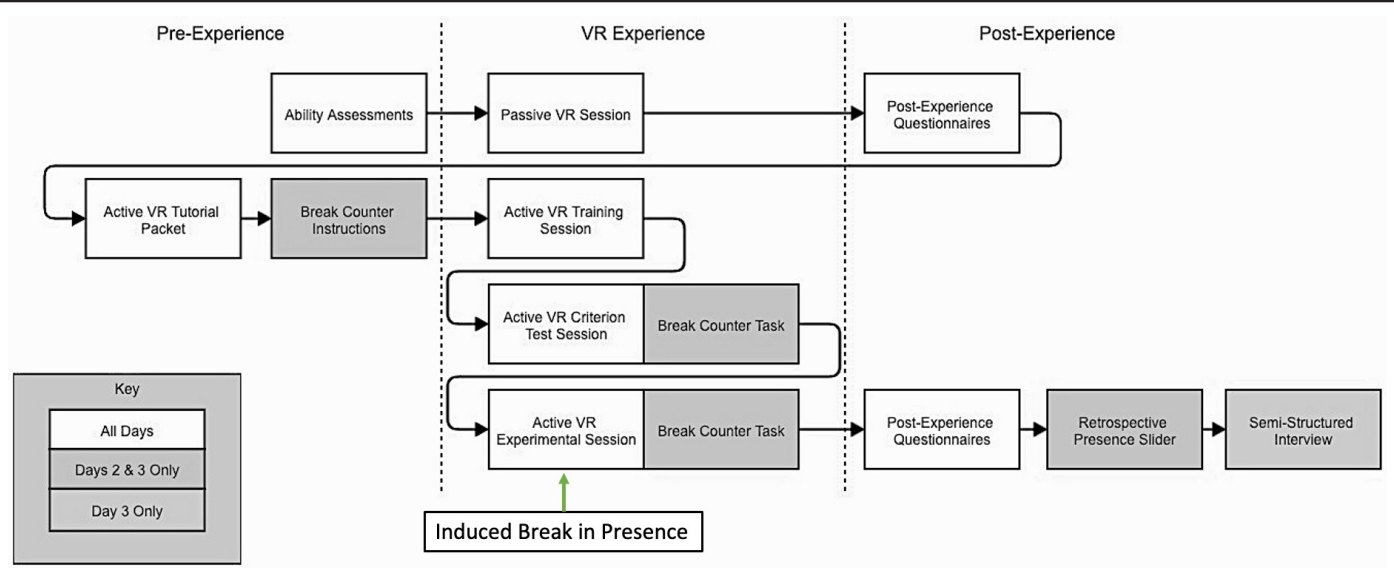

Figure 2. Procedural flow for the research study

sion. Administration of cognitive and perceptual ability measures was distributed across the three days and occurred at the very beginning of each day. The passive VR sessions remained the same across days. The VR tutorial was reviewed on Days 2 and 3 for all participants, but the active VR training session was only conducted for younger participants on Days 2 and 3 if they failed the active VR criterion test. The active VR experimental sessions differed slightly each day:

- Day 1: No temporally-sensitive assessments (baseline)

- Day 2: Break in presence counter and retrospective presence slider

- Day 3: Break in presence counter and retrospective presence slider. Breaks in presence were induced experimentally two times on Day 3, one-third and two-thirds of the way through the session. Breaks were induced by the experimenter using the Vive's outward-facing camera to overlay a digital version of the physical environment into the VR headset as an overt visual reminder of the participant's physical location. The experimenter walked across the participant's field of view, touched the motion tracker on the opposite side of the room, and then returned across the participant's field of view to the experimenter's PC and removed the digital overlay. Following the experimental sessions on Days 2 and 3, participants completed the break susceptibility/recovery questionnaire. The semi-structured interview was conducted at the end of Day 3 , after which participants were debriefed. Older participants were compensated $\$ 90$ total for their time. Younger participants received course credit. Figure 2 shows the procedure.

\section{Results}

\section{Overview of analyses}

Our analyses focused on the following aspects of the spatial presence process for younger and older adults: How long it takes to form spatial presence; the extent that spatial presence is ex- perienced and if it changes over time; how well people maintain presence; and how well people recover from breaks in spatial presence. For more details about how cognitive and perceptual abilities relate to differences in spatial presence, and additional analysis information see McGlynn (2019). Because the experimentally induced break in presence on Day 3 influenced the break counter and retrospective presence slider data, only Day 2 data were used in the analyses that follow.

Table 2 presents an overview of the measures used to address the research questions in this study.

\section{VR traits}

The VR trait data showed that younger adults were significantly higher than older adults in Immersive Tendencies $(\mathrm{t}(47)=3.52, \mathrm{p}=.001)$, indicating that they agreed more with statements regarding their general inclination to become deeply involved in various media (e.g., books, movies). Younger and older adults did not differ significantly in Domain-Specific Interest or Visuo-Spatial Imagery ( $p$ $>$.05). See Table 3 for the means and standard deviations of these measures.

\section{Spatial presence formation}

The first aim of this study was to investigate the spatial presence formation process and potential age-related differences. The Vive controller touchpad collected the vertical position of the thumb every .01 seconds during the video viewing sessions. The data used in these analyses were derived from participants' thumb positions every 1 second. The data ranged from -1.0 to 1.0. with -1.0 to -0.1 indicating physical presence, 0.1 to 1.0 indicating virtual presence, and -0.1 to 0.1 being indeterminant. Presence formation was defined as the amount of time it took for the feeling of virtual presence to first occur. To assess presence formation, the presence slider data were summarized by counting the number of 
Table 2. Research questions and measures used

\begin{tabular}{lcc} 
Research question & Component of interest & \multicolumn{1}{c}{ Measures used } \\
\hline $\begin{array}{l}\text { How long does it take for } \\
\text { presence formation to occur? }\end{array}$ & Presence Formation & $\begin{array}{c}\text { Day 2 Presence Slider } \\
\text { Semi-Structured Interview }\end{array}$ \\
$\begin{array}{l}\text { To what extent do people } \\
\text { experience presence? }\end{array}$ & $\begin{array}{c}\text { MEC-SPQ } \\
\text { Day 2 Presence Slider } \\
\text { Semi-Structured Interview }\end{array}$ \\
$\begin{array}{lc}\text { Once presence has occurred, } \\
\text { how well do people maintain it? }\end{array}$ & $\begin{array}{c}\text { Presence Maintenance } \\
\text { Day 2 Break in Presence Counter } \\
\text { Day 2 Presence Slider }\end{array}$ \\
$\begin{array}{l}\text { If presence is broken, how easy } \\
\text { is it to regain? }\end{array}$ & $\begin{array}{c}\text { Recovery from Breaks in } \\
\text { Presence }\end{array}$ & \begin{tabular}{c} 
Semi-Structured Interview \\
\hline
\end{tabular} \\
\hline
\end{tabular}

participants who first formed presence (i.e., first reported a score in the 0.1 to 1 range) within 10 seconds of the video viewing session. The variable used for the level of presence was the mean score over the course of the session.

Spatial presence occurred quickly for both younger and older adults as indicated by data from the presence slider (Figure 3). The semistructured interview data were consistent with the presence slider data in that almost all participants (45/49) indicated being virtually present within the first 30 seconds of the experience using the presence slider, many saying it occurred "instantly" or "immediately." As shown in Figure 3 , the spatial presence formation patterns were similar for both age groups.

\section{Levels of spatial presence}

Next, we examined the overall level of spatial presence experienced by participants, once presence formation had occurred. Spatial presence was high overall for both younger and older adults as indicated by multiple measures; the data did not provide evidence in support of age-related differences. Slider presence mean scores were significantly higher than the midpoint for both age groups $(p<.05$; see Figure 3 for mean presence level over the course of the session; note that -0.1 to +0.1 were considered indeterminate).

Across days, the MEC-SPQ scores were significantly higher than the midpoint for both age groups across all sub-domains (Figure 4); there were no age-related differences after applying a Bonferroni correction controlling for the number of ANOVAs run $(p=.05 / 6=.008)$. Collapsing

Table 3. Means and standard deviations for VR trait variables

\begin{tabular}{lccc}
\hline Measure & $\begin{array}{c}\text { Younger adults } \\
\text { mean (SD) }\end{array}$ & $\begin{array}{c}\text { Older adults } \\
\text { mean (SD) }\end{array}$ & $\begin{array}{c}\text { All participants } \\
\text { mean (SD) }\end{array}$ \\
\hline $\begin{array}{l}\text { Immersive tendencies } \\
\begin{array}{l}\text { Domain-specific interest } \\
\text { (MEC-SPQ) }\end{array}\end{array}$ & $4.42(.87)$ & $3.57(.80)$ & $4.00(.93)$ \\
$\begin{array}{l}\text { Visuo-spatial imagery } \\
\text { (MEC-SPQ) }\end{array}$ & $3.56(.89)$ & $3.10(.76)$ & $3.33(.85)$ \\
\hline
\end{tabular}

There was a difference between younger and older adults in the number of breaks in presence reported as determined by a Mann-Whitney $U$ test (Figure 5). Younger adults reported a significantly greater number of breaks in presence than older adults (MdnYounger = 3; MdnOlder $=0, U=142.5, \mathrm{I}=.001$ ). Of note is that only 11 of the 25 older 


\section{Spatial Presence: Retrospective Slider}

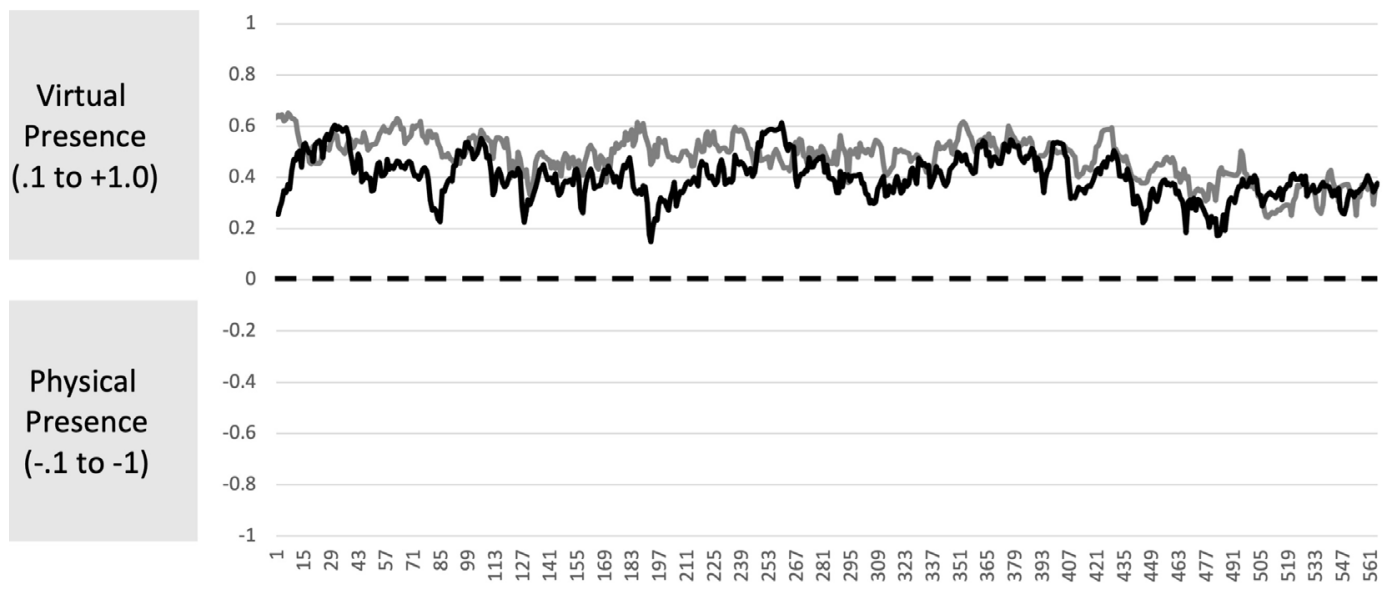

—Older Adults —Younger Adults

Figure 3. Mean retrospective presence slider scores over time for younger and older adults

participants reported at least one break in presence whereas 23 of the 25 younger participants reported at least one break in presence. In sum, presence maintenance was high for both younger and older adults, but younger adults reported a greater number of breaks in presence overall.

\section{Recovery from breaks in presence}

The results on presence formation and level indicated that across both age groups, formation occurred quickly, and the level of presence was high. Age differences were observed in presence maintenance, however, such that younger adults reported more breaks in presence than older adults. Nevertheless, because the total amount of time spent virtually present was still high for both groups, it could have been the case that re-

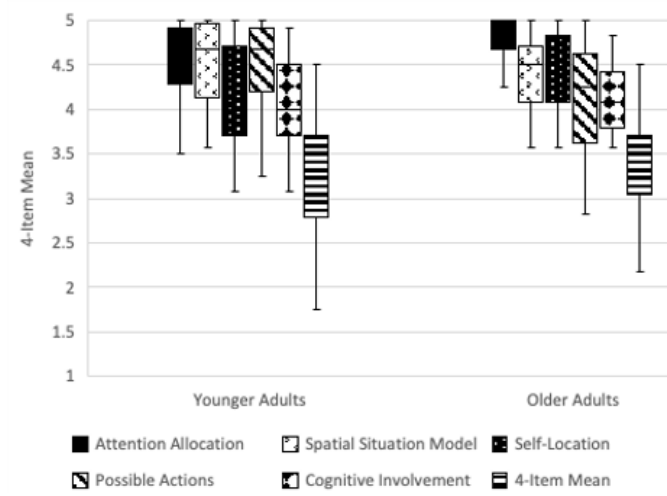

Figure 4. Boxplots for each MEC-spatial presence questionnaire sub-domain for younger and older adults (higher scores indicate greater presence in each sub-domain) covery from breaks in presence occurred rapidly, just as presence formation occurred rapidly.

Break recovery was defined as the ease or difficulty with which participants were able to regain their sense of virtual presence after a break-in presence and the amount of time it took them to do so. To assess break recovery, breaks in presence were experimentally induced on Day 3 of the study. As a manipulation check, we asked participants to describe what they saw when the breaks in presence occurred. Almost all participants $(43 / 49)$ indicated that they saw their physical body, the experimenter's physical body, and/ or the room, suggesting that most participants did realize that they were suddenly seeing the physical environment.

The induced break was effective for most, but not all participants. Participants were asked whether they felt more virtually or physically present during the induced breaks in presence. Most participants (34) said they felt more physically present; 19 of those were younger adults and 15 were older adults. Some participants (13) said they felt more virtually present, and 2 said they felt both physical and virtual simultaneously regarding the first induced break. Regarding the second induced break, 38 said they felt more physically present; 22 of those were younger adults and 16 were older adults. Again, some participants (11) said they felt more virtually present. Only one "Other" response came from an older adult (of the 31 total older adult responses across both induced breaks), whereas 10 "Other" responses came from younger adults (of the 41 total young- 


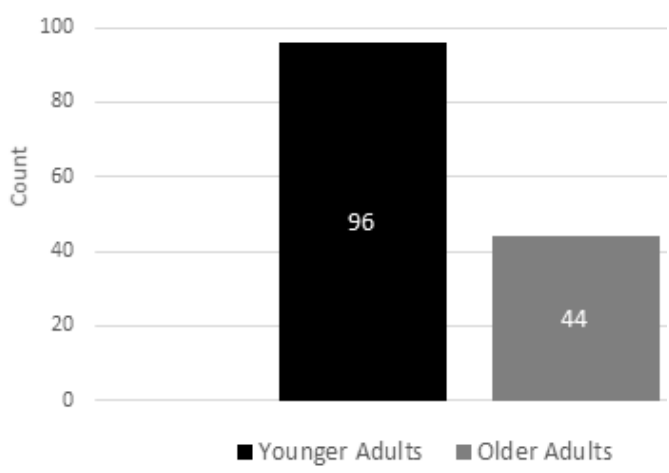

Figure 5. Total number of breaks in presence reported for younger and older adults

er responses across both breaks). Therefore, we found limited evidence suggesting age-related differences in break recovery. Rather, most participants felt that recovering from breaks in presence was easy, which is consistent with the finding that younger adults reported more breaks in presence but still spent a large proportion of their total time present in the virtual environment.

In the semi-structured interview, participants were asked how difficult they found it to be to regain their sense of virtual presence after each break occurred. Regarding the first induced break overall, 29 of the 34 participants who said they felt more physically present said it was easy to recover from. Regarding the second induced break, 32 of the 38 participants said it was easy to recover from.

\section{Discussion}

Research has demonstrated a wide range of successful applications of VR, including training (Satava, 1995); healthcare, and wellness (Chirico et al., 2016; Kim et al., 2013; Satava, 1995); and entertainment (Bates, 1992). Many of these applications have the potential to benefit older adults' physical, cognitive, and socio-emotional well-being. We developed the Magnet Model of Spatial Presence (MMSP) to better explain how person factors influence different aspects of spatial presence (i.e., presence formation, maintenance, break recovery). The MMSP hypothesizes that people differ in the ease with which they can experience presence (i.e., presence formation), how present they become (i.e., presence level), their susceptibility to breaks in presence (i.e., presence maintenance), and how well they recover after a break-in presence has occurred.

Given that perception and attention are key components of the spatial presence process. Younger and older adults might experience spatial presence differently given age-related changes in these abilities (Czaja et al., 2019). In this study, almost all participants appeared to become virtually present very rapidly, even within the first few seconds of the VR session. One possibility, consistent with the MMSP, is that because the VR system was so immersive, the threshold for one's perceived self-location to cross over into the virtual environment was so low that presence formation was almost instantaneous. Prior to this study, it was unclear how long it took people to go through this presence formation process to first achieve the sense of presence in the virtual environment. Although many models of presence acknowledged that presence formation occurs (Bystrom et al., 1999 1999; Nunez, 2007; Regenbrecht, Schubert, \& Friedmann, 1998; Wirth et al., 2007), the most common, and almost exclusively used method of measuring presence (postexperience questionnaires) is not conducive to understanding presence formation.

Another key finding from this study was that people experienced high levels of presence in virtual reality. We controlled the level of immersiveness to evaluate person factors. We held the immersiveness of the system constant, used a highly immersive system, and used theoretically-grounded post-experience presence questionnaires in addition to novel methods to measure presence levels. Our findings of high levels of presence were shown through the post-experience presence questionnaires, for which nearly every subdomain on every day was significantly higher than the mid-point of those scales. The levels observed in this study were higher than observed in the development of the MEC-SPQ (Vorderer et al., 2004), likely due to their inclusion of nonimmersive media. High levels of presence were also observed using the presence slider means, a novel method of presence measurement.

High levels of presence were expected because we used a highly immersive system. Less understood was if levels of presence would persist over time. If VR could have a novelty effect, the feeling of presence could be diminished over time as people become familiar with the sensation. This could have implications for the use of VR as a tool for interventions or training because these types of applications (whether in VR or not) often require extensive repetition. Although some VR interventions are likely to last longer than the duration that participation in this study required, our findings provide evidence that high levels of spatial presence in immersive VR do not diminish rapidly as people spend more time and gain more experience with the system. This finding, in conjunction with observations that immersive VR tends to result in more enjoyment compared to non-immersive VR (IJsselsteijn, Kort, Westerink, Jager, \& Bonants, 2006) suggests that immersive VR should be used to maximize the effectiveness of VR applications, yet less immersive systems could be sufficient, depending on the application goal. 
A key contribution of this study was in providing insights regarding maintenance of presence through existing and novel measures of presence that were sensitive to within-experience fluctuations. Overall, people felt virtually present for the majority of the time they spent in VR, as indicated by both the presence slider and the semi-structured interview. Additionally, on average, people reported only 2.8 breaks in presence during the 10 -minute session. This was slightly lower than what has been previously reported (Slater \& Steed, 2000), possibly due to the inclusion of older adults. Given that Slater \& Steed (2000) findings were published over 20 years ago, it is likely that their system used a less immersive head-mounted display compared to the one used in this study, which probably influences breaks in presence.

During a VR experience, many factors can pull focus away from the virtual environment and cause a break in the presence (e.g., headset weight, noise, mind-wandering). For interventionists, researchers, and VR system designers, it is essential to consider just how intrusive breaks in presence can be to the overall experience. A novel method of experimentally inducing breaks in presence was developed for this study, whereby a digital overlay of the physical environment was projected into the headset two times throughout the 10-minute session on one of the studies days. Almost all participants indicated that they saw their physical environment during the induced break. For slightly fewer people (though still most of the participants overall) this induced break was effective, indicating that when it occurred, they felt more physically present. Of these individuals, almost all said that it was easy to recover from these breaks in presence.

Some of the measures we used to assess recovery from breaks in presence were not reliable. For example, one of the response options to the Break Susceptibility and Recovery Questionnaire was "N/A: I did not experience a break in presence" and some individuals chose that option for some of the questions but not others. If they did not experience a break in presence, they should have chosen that option for all of the items. Additionally, the presence slider did not capture the number of seconds it took for people to recover from the induced breaks. The exact inception and length of the induced breaks were not specific enough to be able to calculate this with a high degree of reliability. With some adjustments, these measures have the potential to be effective assessments of break recovery time. However, because there was evidence of rapid presence formation and high presence maintenance overall, the interview responses suggesting quick break recovery times are likely valid.
Despite the many VR applications that can benefit older adults (Cherniack, 2011; Hodges et al., 1995; Hoffman et al., 2004; Molina et al., 2014; Satava, 1995; Schultheis \& Rizzo, 2001; Sisto, Forrest, \& Glendinning, 2002; Wilson, Foreman, \& Stanton, 1997), older adults are often not included in spatial presence research or VR system design. This limits the potential for VR applications and limits the generalizability of theoretical spatial presence models. Despite a variety of age-related cognitive and perceptual changes that might have been expected to have an impact on the spatial presence process (Sean A McGlynn, Sundaresan, \& Rogers, 2018), we found that younger and older adults demonstrated similar spatial presence processes. Presence formation occurred very quickly for older as well as younger participants. Moreover, there was little evidence to suggest that levels of presence differed across age groups. Previous research found both a negative relationship between presence and age (Bangay \& Preston, 1998), and a positive relationship (Dilanchian, Adringa, \& Boot, 2021; Schuemie, Abel, van der Mast, Krijn, \& Emmelkamp, 2005). However, these studies were limited in the spatial presence measurement method used and in the range of ages in their samples. Given our findings, using multidimensional measures of presence, that older adults can experience high levels of presence in immersive VR, it is possible (and likely) that they will experience the benefits of VR applications.

It was hypothesized that younger adults would experience lower presence maintenance than older adults. Our data support this hypothesis. Younger adults reported significantly more breaks in presence than older adults. Many older adults did not report any breaks in presence whatsoever, perhaps due to age-related differences in divided attention abilities. That is, once presence formation had occurred, younger adults might have been more easily able to split their focus and alternate their sense of being across the virtual and physical environment throughout the experience, resulting in more breaks in presence. This hypothesis is also supported by the findings of an earlier analysis, in which we found that a greater number of breaks in presence was associated with higher focused attention scores (McGlynn, 2019), as opposed to lower focused attention scores, possibly related to individuals being more distractible.

However, more breaks in presence did not result in a significant reduction in the amount of time spent virtually present. Both age groups had similar presence slider and interview responses. The likely explanation is that presence formation and break recovery occurred so quickly that the total percentages of time spent virtual were similar 
Table 4. Summary of insights and recommendations

\begin{tabular}{|c|c|}
\hline Topic & Insights and recommendations \\
\hline $\begin{array}{l}\text { Virtual reality } \\
\text { system/experience }\end{array}$ & $\begin{array}{l}\text { - Immersive VR elicits high levels of presence across a range of users } \\
\text { - } \quad \text { Levels of presence persist over time (short periods) and with VR experience } \\
\text { - } \quad \text { Non-photorealistic experiences can elicit high levels of presence } \\
\text { - } \quad \text { Qualities of the system (e.g., wires) and experience setup (e.g., physical objects) } \\
\text { can cause breaks in presence } \\
\text { - Inconsistencies in the virtual environment (e.g., physical objects passing through } \\
\text { each other) can cause breaks in presence }\end{array}$ \\
\hline $\begin{array}{l}\text { Presence } \\
\text { measurement }\end{array}$ & $\begin{array}{l}\text { - Questionnaires capture levels of presence, are unobtrusive and are appropriate } \\
\text { - } \quad \text { Queross age groups - useful if temporal fluctuations in presence are not of interest } \\
\text { information derived from presence questionnaires may be limited when using } \\
\text { highly immersive systems } \\
\text { Break in presence counters capture extreme drops in presence but do not } \\
\text { necessarily reflect overall presence maintenance } \\
\text { Breaks in presence counters are relatively unobtrusive but people may forget to } \\
\text { - } \text { - Somert them some of the time } \\
\text { - } \quad \text { Break in presence counters should only be used in conjunction with other } \\
\text { methods, but can be an effective method for probing causes of presence breaks } \\
\text { Presence sliders are valid to administer retrospectively and are unobtrusive using } \\
\text { this method of administration (though some input modifications may be necessary } \\
\text { for them to be appropriate for older adults) } \\
\text { If multi-dimensionality is not of interest, presence sliders are the single best method } \\
\text { for capturing the entire spatial presence process }\end{array}$ \\
\hline
\end{tabular}

across age groups, in spite of younger adults reporting more breaks in presence. Crucially, age differences in presence maintenance as measured by the break in presence counter did not appear to be due to prospective memory failures, which would have been expected to be more prevalent in older adults than in than younger adults. Most participants did not find it difficult to remember to report breaks in presence. Also, the majority of older participants who did not report any breaks in presence did not show breaks in presence on the presence slider (which was not a prospective memory task).

A break in presence is essentially a shift in attention from the virtual to the physical environment that results in returning to feeling 'there' in the physical environment. It was hypothesized that older adults might have a more difficult time recovering from breaks in presence due to differences in shifting attention abilities. Although the only assessment of recovery from breaks in presence was an interview question, the evidence did not support this hypothesis. Most participants reported recovering quickly from breaks in presence.

For certain types of interventions to be effective, the person needs to enjoy and be engaged in the intervention task. In this study, we found that both younger and older adults were highly engaged in the VR task consistently over the course of the study and enjoyed their experiences in general. This was consistent with previous findings (Sakhare, Yang, Stradford, et al., 2019), and of particular interest for the older adult group because of the relatively limited information, we have regarding older adults' interactions with VR. That participants were engaged and continued to be engaged in this cognitive-perceptual-motor VR experience, provides evidence that these types of experiences can be used for VR training and interventions for people across a range of abilities.

The experience of conducting this study and the study findings provide insights, and related recommendations, regarding using VR with people of all ages. We have provided a summary of these insights and recommendations in Table 4. We hope this information will be useful for guiding researchers, interventionists, and designers of VR systems and experiences. Some future directions for applications of VR for older adults include products and services to facilitate real-world orientation (e.g., virtual tourism), education (e.g., VR-based lessons, gamification), health (e.g., pain management, psychotherapy, rehabilitation, physical and cognitive exercise, gait/balance training), entertainment (e.g., leisure experiences, visiting museums), social connectedness (e.g., collaborative games, group activities; Guttentag, 2010; Hoffman et al., 2004; Seifert \& Schlomann, 2021; Sisto, Forrest, \& Glendinning, 2002), as well as completing enhanced activities of daily living (EADLs; Dilanchian, Andringa, \& Boot, 2021).

\section{Conclusion}

This study provided substantial knowledge to the theory of spatial presence, specifically, toward expanding models of spatial presence beyond 
levels and broadening our understanding of the role of person factors in the presence process. VR has exciting potential applications in a seemingly endless number of contexts. Our results provide evidence that in immersive $\mathrm{VR}$, both younger and older people experience spatial presence rapidly, consistently, and to a high degree. Because experiencing spatial presence is critical for VR applications, these applications will likely be effective for people of varying characteristics and abilities.

\section{Acknowledgements}

This paper was based on a dissertation submitted by Dr. McGlynn to the School of Psychology at the Georgia Institute of Technology. Dr. McGlynn currently works at Microsoft. The authors would like to especially thank the following individuals for their incredible guidance, contributions, and support of this project: Dr. Bruce N. Walker, Dr. Maribeth G. Coleman, Dr. Scott D. Moffat, Dr. Eric H. Schumacher, Jon Sanford, M. Arch, and Lauren Santos.

\section{Funding}

The research was supported by a Ruth L. Kirschstein National Research Award (NRSA) Institutional Research Training Grant from the National Institutes of Health (National Institute on Aging) T32AG000175, as well as by the Center for Research and Education on Aging and Technology Enhancement (CREATE; create-center.org; PO1AG17211) through a CREATE pilot grant.

\section{References}

Bangay, S., \& Preston, L. (1998). An investigation into factors influencing immersion in interactive virtual reality environments. Studies in health technology and informatics, 43-51.

Bates, J. (1992). Virtual reality, art, and entertainment. Presence: Teleoperators \& Virtual Environments, 1(1), 133-138.

Baumann, J. (1993). Military applications of virtual reality. Retrieved from http://www.hitl.washington. edu/projects/knowledge_base/virtual-worlds/EVE/ II.G.Military.html

Biocca, F. (1992). Communication within virtual reality: Creating a space for research. Journal of communication, 42(4), 5-22. doi:https://doi. org/10.1111/j.1460-2466.1992.tb00810.x

Bruun-Pedersen, J. R., Serafin, S., Maculewicz, J., \& Kofoed, L. B. (2016). Designing recreational virtual environments for older adult nursing home residents: How nature and content matter for improving augmented exercise experiences. Paper presented at the Proceedings of the Audio Mostly 2016, Norrköping, Sweden. https://doi. org/10.1145/2986416.2986455

Bystrom, K.-E., Barfield, W., \& Hendrix, C. (1999). A conceptual model of the sense of presence in virtual environments. Presence: Teleoperators and virtual environments, 8(2), 241-244.

Cherniack, E. P. (2011). Not just fun and games: Applications of virtual reality in the identification and rehabilitation of cognitive disorders of the elderly. Journal of Disability Rehabilitation: Assistive Technology, 6(4), 283-289.

Chirico, A., Lucidi, F., De Laurentiis, M., Milanese, C., Napoli, A., \& Giordano, A. (2016). Virtual reality in health system: Beyond entertainment. A mini-review on the efficacy of VR during cancer treatment.
Journal of cellular physiology, 231(2), 275-287.

Czaja, S. J., Boot, W. R., Charness, N., \& Rogers, W. A. (2019). Designing for Older Adults: Principles and Creative Human Factors Approaches (3rd ed.). Boca Raton, FL: CRC Press.

Czaja, S. J., Charness, N., Fisk, A. D., Hertzog, C., Nair, S. N., Rogers, W. A., \& Sharit, J. (2006). Factors predicting the use of technology: Findings from the Center for Research and Education on Aging and Technology Enhancement (CREATE). . Psychology and Aging, 21(2), 333-352. https://doi. org/10.1037/0882-7974.21.2.333

De Bruin, E. D., Schoene, D., Pichierri, G., \& Smith, S. T. (2010). Use of virtual reality technique for the training of motor control in the elderly. Zeitschrift für Gerontologie und Geriatrie, 43(4), 229-234.

Dilanchian, A. T., Andringa, R., \& Boot W. R. (2021). A pilot study exploring age differences in presence, workload, and cybersickness in the experience of immersive virtual reality environments. Frontiers in Virtual Reality, 2, 736793. https://doi.org/10.3389/ frvir.2021.736793

Edwards, J. D., Vance, D. E., Wadley, V. G., Cissell, G. M., Roenker, D. L., \& Ball, K. K. (2005). Reliability and validity of useful field of view test scores as administered by personal computer. Journal of clinical and experimental neuropsychology, 27(5), 529-543.

Eisapour, M., Cao, S., Domenicucci, L., \& Boger, J. (2018). Participatory design of a virtual reality exercise for people with mild cognitive impairment. Extended Abstracts of the $2018 \mathrm{CHI}$ Conference on Human Factors in Computing Systems, CS15:11-CS15:19. https://doi.org/10.1145/3170427.3174362

French, J. W., Ekstrom, R. B., \& Price, L. A. (1963). Manual for kit of reference tests for cognitive factors. Princeton NJ: Educational Testing Service Princeton NJ.

Gavish, N., Gutiérrez, T., Webel, S., Rodríguez, J., Peveri, M., Bockholt, U., \& Tecchia, F. (2015). Evaluating virtual reality and augmented reality training for industrial maintenance and assembly tasks. Interactive Learning Environments, 23(6), 778-798.

Giovannetti, T., Yamaguchi, T., Roll, E., Harada, T., Rycroft, S. S., Divers, R., . . . Mis, R. (2019). The virtual kitchen challenge: Preliminary data from a novel virtual reality test of mild difficulties in everyday functioning. Aging, Neuropsychology, and Cognition, 26(6), 823-841. https://doi.org/10.1080/13825 585.2018.1536774

Guttentag, D. A. (2010). Virtual reality: Applications and implications for tourism. Tourism Management, 31(5), 637-651.

Hart, S. G., \& Staveland, L. E. (1988). Development of NASA-TLX (Task Load Index): Results of empirical and theoretical research. Advances in psychology, 52, 139-183. 
Hodges, L. F., Kooper, R., Meyer, T. C., Rothbaum, B. O., Opdyke, D., de Graaff, J. J., . . . North, M. M. (1995). Virtual environments for treating the fear of heights. Computer, 28(7), 27-34.

Hoffman, H. G., Richards, T. L., Coda, B., Bills, A. R., Blough, D., Richards, A. L., \& Sharar, S. R. (2004). Modulation of thermal pain-related brain activity with virtual reality: evidence from fMRI. Neuroreport, 15(8), 1245-1248.

IJsselsteijn, W., de Ridder, H., Hamberg, R., Bouwhuis, D., \& Freeman, J. (1998). Perceived depth and the feeling of presence in 3DTV. Displays, 18(4), 207-214.

IJsselsteijn, W. A., Kort, Y. d., Westerink, J., Jager, M. d., \& Bonants, R. (2006). Virtual fitness: stimulating exercise behavior through media technology. Presence: Teleoperators Virtual Environments, 15(6), 688-698.

Kim, J., Kim, K., Kim, D. Y., Chang, W. H., Park, C.-I., Ohn, S. H., . . . Kim, I. Y. (2007). Virtual environment training system for rehabilitation of stroke patients with unilateral neglect: Crossing the virtual street. CyberPsychology \& Behavior, 10(1), 7-15.

Kim, J., Son, J., Ko, N., \& Yoon, B. (2013). Unsupervised virtual reality-based exercise program improves hip muscle strength and balance control in older adults: A pilot study. Archives of physical medicine and rehabilitation, 94(5), 937-943.

Kim, J. H., Jang, S. H., Kim, C. S., Jung, J. H., \& You, J. H. (2009). Use of virtual reality to enhance balance and ambulation in chronic stroke: A double-blind, randomized controlled study. American Journal of physical medicine \& rehabilitation, 88(9), 693-701.

Kim, T., \& Biocca, F. (1997). Telepresence via television: Two dimensions of telepresence may have different connections to memory and persuasion. Journal of Computer-Mediated Communication, 3(2), 0-0.

Kothgassner, O. D., Goreis, A., Kafka, J. X., Hlavacs, H., Beutl, L., Kryspin-Exner, I., \& Felnhofer, A. (2018). Agency and gender influence older adults' presence-related experiences in an interactive virtual environment. Cyberpsychology, Behavior, and Social Networking, 21, 5.

McGee, J. S., van der Zaag, C., Buckwalter, J. G., Thiébaux, M., Van Rooyen, A., Neumann, U., . . - Rizzo, A. A. (2000). Issues for the assessment of visuospatial skills in older adults using virtual environment technology. CyberPsychology \& Behavior, 3(3), 469-482.

McGlynn, S. A. (2019). Investigating age-related differences in spatial presence formation and maintenance in virtual reality. Doctoral dissertation. Georgia Institute of Technology. Atlanta, GA.

McGlynn, S. A., Sundaresan, R. M., \& Rogers, W. A. (2018). Investigating age-related differences in spatial presence in Vvrtual reality. Paper presented at the Proceedings of the Human Factors and Ergonomics Society Annual Meeting.

Molina, K. I., Ricci, N. A., de Moraes, S. A., \& Perracini, M. R. (2014). Virtual reality using games for improving physical functioning in older adults: A systematic review. Journal of neuroengineering and rehabilitation, 11(1), 156.

Nunez, D. (2007). A capacity limited, cognitive constructionist model of virtual presence. (Doctoral Dissertation). University of Cape Town,
Plante, T. G., Aldridge, A., Bogden, R., \& Hanelin, C. (2003). Might virtual reality promote the mood benefits of exercise? Computers in Human Behavior, 19(4), 495-509.

Regenbrecht, H. T., Schubert, T. W., \& Friedmann, F. (1998). Measuring the sense of presence and its relations to fear of heights in virtual environments. International Journal of Human-Computer Interaction, 10(3), 233-249.

Sakhare, A. R., Yang, V., Stradford, J., Tsang, I., Ravichandran, R., \& Pa, J. (2019). Cycling and spatial navigation in an enriched, immersive $3 \mathrm{D}$ virtual park environment: A feasibility study in younger and older adults. Frontiers in Aging Neuroscience, 11, 218. https://doi.org/10.3389/fnagi.2019.00218

Sanchez-Cubillo, I., Perianez, J., Adrover-Roig, D., Rodriguez-Sanchez, J., Rios-Lago, M., Tirapu, J., \& Barcelo, F. (2009). Construct validity of the Trail Making Test: Role of task-switching, working memory, inhibition/interference control, and visuomotor abilities. Journal of the International Neuropsychological Society, 15(3), 438-450.

Satava, R. M. (1995). Medical applications of virtual reality. Journal of Medical Systems, 19(3), 275-280.

Schneider, S. M., \& Hood, L. E. (2007). Virtual reality: a distraction intervention for chemotherapy. Paper presented at the Oncology Nursing Forum.

Schroeder, R. (2002). Social interaction in virtual environments: Key issues, common themes, and a framework for research. The social life of avatars: Presence and interaction in shared virtual environments, 1.

Schubert, T., Friedmann, F., \& Regenbrecht, H. (2001). The experience of presence: Factor analytic insights. Presence: Teleoperators and virtual environments, 10(3), 266-281.

Schuemie, M., Abel, B., van der Mast, C., Krijn, M., \& Emmelkamp, P. (2005). The effect of locomotion technique on presence, fear and usability in a virtual environment. Paper presented at the EUROMEDIA.

Schultheis, M. T., \& Rizzo, A. A. (2001). The application of virtual reality technology in rehabilitation. Rehabilitation Psychology, 46(3), 296.

Seifert, A. \& Schlomann, A. (2021). The use of virtual and augmented reality by older adults: Potentials and challenges. Frontiers in Virtual Reality, 2, 51. https://doi.org/10.3389/frvir.2021.639718

Sisto, S. A., Forrest, G. F., \& Glendinning, D. (2002). Virtual reality applications for motor rehabilitation after stroke. Topics in Stroke Rehabilitation, 8(4), 11-23.

Slater, M., \& Steed, A. (2000). A virtual presence counter. Presence: Teleoperators and virtual environments, 9(5), 413-434.

Slater, M., \& Wilbur, S. (1997). A framework for immersive virtual environments (FIVE): Speculations on the role of presence in virtual environments. Presence: Teleoperators and virtual environments, 6(6), 603-616.

Stanney, K., \& Salvendy, G. (1998). Aftereffects and sense of presence in virtual environments: Formulation of a research and development agenda. International Journal of Human-Computer Interaction, 10(2), 135-187.

Stanney, K. M., Mourant, R. R., \& Kennedy, R. S. (2006). Human factors issues in virtual environments: A review of the literature. Human Factors, 7(4). 
Steuer, J. (1992). Defining virtual reality: Dimensions determining telepresence. Journal of communication, 42(4), 73-93.

Sylaiou, S., Mania, K., Karoulis, A., \& White, M. (2010). Exploring the relationship between presence and enjoyment in a virtual museum. International journal of human-computer studies, 68(5), 243-253.

Thompson, E. (2007). Positive and negative affect schedule (PANAS): Development and validation of an internationally reliable short-form of the positive and negative affect schedule short-form. Journal of Cross-Cultural Psychology, 38. https://doi. org/10.1177/0022022106297301

Tombaugh, T. N. (2004). Trail Making Test A and B: Normative data stratified by age and education. Archives of clinical neuropsychology, 19(2), 203-214.

Verbruggen, F., Liefooghe, B., \& Vandierendonck, A. (2004). The interaction between stop signal inhibition and distractor interference in the flanker and Stroop task. Acta psychologica, 116(1), 21-37.

Vorderer, P., Wirth, W., Gouveia, F. R., Biocca, F., Saari, T., Jäncke, F., . . . Hartmann, T. (2004). MEC spatial presence questionnaire (MEC-SPQ): Short docu- mentation and instructions for application. Retrieved from https://academic.csuohio.edu/kneuendorf/frames/MECFull.pdf

Wallis, G., \& Tichon, J. (2013). Predicting the efficacy of simulator-based training using a perceptual judgment task versus questionnaire-based measures of presence. Presence: Teleoperators and virtual environments, 22(1), 67-85.

Wickens, C. D. (1992). Virtual reality and education. Paper presented at the IEEE International Conference on Systems, Man and Cybernetics.

Wilson, P. N., Foreman, N., \& Stanton, D. (1997). Virtual reality, disability and rehabilitation. Disability and Rehabilitation Psychology, 19(6), 213-220.

Wirth, W., Hartmann, T., Böcking, S., Vorderer, P., Klimmt, C., Schramm, H., . . Gouveia, F. R. (2007). A process model of the formation of spatial presence experiences. Media psychology, 9(3), 493-525.

Witmer, B. G., \& Singer, M. J. (1998). Measuring presence in virtual environments: A presence questionnaire. Presence: Teleoperators and virtual environments, 7(3), 225-240. 